\title{
Energy-mediated vs. ammonium-regulated gene expression in the obligate ammonia-oxidizing bacterium, Nitrosococcus oceani
}

\author{
Lisa Y. Stein ${ }^{1 *}$, Mark A. Campbell ${ }^{2}$ and Martin G. Klotz ${ }^{2 *}$ \\ 1 Department of Biological Sciences, University of Alberta, Edmonton, AB, Canada \\ ${ }^{2}$ Department of Biology, University of North Carolina, Charlotte, Charlotte, NC, USA
}

\section{Edited by:}

Boran Kartal, Radboud University, Netherlands

\section{Reviewed by:}

James Hemp, California Institute of Technology, USA

Pilar Junier, University of Neuchâtel, Switzerland

\section{*Correspondence:}

Lisa Y. Stein, Department of Biological Sciences, University of Alberta, CW 405 Bio Sci Bldg, Edmonton, AB T6G 2E9, Canada e-mail: lisa.stein@ualberta.ca; Martin G. Klotz, Department of Biology, University of North Carolina, 9201 University City Blvd, Charlotte, NC 28223, USA e-mail:mklotz@uncc.edu
Ammonia serves as the source of energy and reductant and as a signaling molecule that regulates gene expression in obligate ammonia-oxidizing chemolithotrophic microorganisms. The gammaproteobacterium, Nitrosococcus oceani, was the first obligate ammonia-oxidizer isolated from seawater and is one of the model systems for ammonia chemolithotrophy. We compared global transcriptional responses to ammonium and the catabolic intermediate, hydroxylamine, in ammonium-starved and non-starved cultures of $N$. oceani to discriminate transcriptional effects of ammonium from a change in overall energy and redox status upon catabolite availability. The most highly expressed genes from ammonium- or hydroxylamine-treated relative to starved cells are implicated in catabolic electron flow, carbon fixation, nitrogen assimilation, ribosome structure and stress tolerance. Catabolic inventory-encoding genes, including electron flow-terminating Complexes IV, FoF1 ATPase, transporters, and transcriptional regulators were among the most highly expressed genes in cells exposed only to ammonium relative to starved cells, although the differences compared to steady-state transcript levels were less pronounced. Reduction in steady-state mRNA levels from hydroxylamine-treated relative to starved-cells were less than five-fold. In contrast, several transcripts from ammonium-treated relative to starved cells were significantly less abundant including those for forward Complex I and a gene cluster of cytochrome $c$ encoding proteins. Identified uneven steady-state transcript levels of co-expressed clustered genes support previously reported differential regulation at the levels of transcription and transcript stability. Our results differentiated between rapid regulation of core genes upon a change in cellular redox status vs. those responsive to ammonium as a signaling molecule in $N$. oceani, both confirming and extending our knowledge of metabolic modules involved in ammonia chemolithotrophy.

Keywords: Nitrosococcus, ammonia-oxidizing bacteria, ammonium, hydroxylamine, redox, signaling, global gene expression, microarray

\section{INTRODUCTION}

Obligate ammonia-oxidizing chemolithotrophic bacteria (AOB) facilitate key transformations in the global nitrogen cycle that interconnect nitrification, denitrification and ammonification (Klotz and Stein, 2011; Stein and Klotz, 2011; Simon and Klotz, 2013). When facilitated by AOB, all of these processes take place under oxic conditions because the first (mono-oxygenation of ammonia) and last (disposal of electrons) steps of catabolic electron flow require free molecular oxygen. $\mathrm{AOB}$ obtain all of their energy and reductant by catabolic oxidation of ammonia to nitrite, the first in the two-step nitrification process historically referred to as nitritation. Thus, $\mathrm{AOB}$ consume ammonia and oxygen for both maintenance of proton-motive force and growth via autotrophic chemosynthesis (Arp et al., 2002).

Ammonia oxidation is facilitated by two dedicated enzyme complexes that were once considered unique to AOB (Arp et al., 2002): ammonia monooxygenase (AMO, amoCAB,
EC:1.14.99.39) and hydroxylamine dehydrogenase (HAO, haoA, EC:1.7.2.6). However, in recent times both AMO and HAO complexes have been identified in many diverse genome backgrounds (Klotz and Stein, 2008; Klotz et al., 2008; Sayavedra-Soto et al., 2011; Tavormina et al., 2011, 2013; Coleman et al., 2012; Hanson et al., 2013; Simon and Klotz, 2013). When expressed together in non-chemolithotrophs, such as methane-oxidizing bacteria (MOB; including Proteobacteria and Verrucomicrobia), these two protein complexes facilitate nitritation; however, the electrons extractable from hydroxylamine cannot be used to support growth via chemolithotrophic catabolism (Klotz and Stein, 2011; Stein and Klotz, 2011). Gene expression studies demonstrated that the haoA-associated gene $h a o B$, adjacent to haoA and formerly known as orf2 (Bergmann et al., 2005), is co-expressed with haoA in the genomes of nitritating gammaproteobacterial AOB and MOB (Poret-Peterson et al., 2008; Campbell et al., 2011b). However, in order to utilize the electrons extracted from 
hydroxylamine during nitritation, $\mathrm{AOB}$ but not nitritating $\mathrm{MOB}$ employ the cytochrome $c$ protein, $c_{\mathrm{M}} 552(c y c B)$ as a cognizant quinone reductase (Elmore et al., 2007; Kim et al., 2008) that either directly interacts with $\mathrm{HAO}$ or obtains electrons indirectly via cytochrome $c 554$ (cycA) (Hooper et al., 2005; Klotz et al., 2008; Kern et al., 2011; Simon and Klotz, 2013). Earlier results indicated that the hao $A$ and $c y c A B$ genes are under control of different promoters in N. europaea (Sayavedra-Soto et al., 1994; Arp et al., 2002; Hommes et al., 2002), however, gammaproteobacterial $\mathrm{AOB}$ such as $N$. oceani appear to produce distinct hao $A B, c y c A B$ and hao $A B-c y c A B$ transcripts indicating complex regulation similar to what was reported for the regulation of genes in the amo gene cluster (El Sheikh and Klotz, 2008; El Sheikh et al., 2008). Cytochrome $c_{\mathrm{M}} 552$ belongs to a large superfamily of membraneassociated cytochrome $c$ proteins $(\mathrm{NapC} / \mathrm{NrfH})$ that exchange electrons with the quinone/quinol pool (Bergmann et al., 2005; Simon and Klotz, 2013). Generally in bacterial genomes, the $c y c B$ gene encoding $c_{\mathrm{M}} 552$ is clustered with other genes encoding catalytic periplasmic proteins that facilitate reduction of nitrogen oxides such as nitrate reductase (nap), nitrite reductase ( $n r f)$, and/or homologues of cytochrome $c 554$ that function as nitric oxide reductases (Upadhyay et al., 2006; Klotz and Stein, 2011; Simon and Klotz, 2013).

Although the ever-increasing number of sequenced microbial genomes has revealed that amoCAB, hao $A B$, and $c y c A B$ genes are not unique to AOB (Arp et al., 2007), it appears that ammonia-dependent chemolithotrophy requires the presence and co-expression of all of these gene clusters (Klotz and Stein, 2011). So far, only the gene encoding the small red-copper protein nitrosocyanin, ncyA, (Arciero et al., 2002; Basumallick et al., 2005) has been identified in the genomes of all AOB with the exception of the oligotrophic Nitrosomonas sp. Is79 strain (Bollmann et al., 2012). The ncyA gene is conspicuously absent from other microbes including non-chemolithotrophic nitritating bacteria like the MOB (Campbell et al., 2011b; Klotz and Stein, 2011) and chemolitotrophic nitritating Thaumarchaeota (Walker et al., 2010). As AOB have two nitritation-dependent pathways that result in production of nitric and nitrous oxides, one starting with hydroxylamine oxidation and the other with nitrite reduction, this activity represents a significant drain to the redox status of the bacteria (Stein, 2011). Therefore, electron flow into and out of the quinone pool needs to be tightly regulated, perhaps by employing the product of the ncyA gene as a redox sensitive switch that directs electrons extracted by HAO to different acceptor proteins. However, this hypothesis remains to be tested.

To date, there is no clear conceptual understanding of the regulation of the amoCAB, hao $A B, c y c A B$, and $n c y A$ genes by cellular redox status and/or by general signaling molecules like ammonium (Sayavedra-Soto et al., 1996; Stein et al., 1997; Bollmann et al., 2005; Wei et al., 2006) or nitrogen oxides (Cho et al., 2006; Beyer et al., 2009; Cua and Stein, 2011; Kartal et al., 2012) and evidence of differential regulation of these gene sets in different genomic backgrounds has increased with every study. For instance, some studies of Nitrosomonas europaea ATCC 19718 report increased transcription of amoCAB genes and protein synthesis upon exposure to ammonium (Hyman and Arp, 1995;
Sayavedra-Soto et al., 1996; Stein et al., 1997), whereas another study comparing expression levels between ammonium-starved and growing cells showed unvaried amoCAB transcript levels (Wei et al., 2006).

According to the current literature, the gammaproteobacterial genus Nitrosococcus is exclusively represented by marine and high salt-tolerant AOB (O'Mullan and Ward, 2005; Campbell et al., 2011a). In contrast to genomes of betaproteobacterial AOB that encode multiple, nearly identical copies of $a m o C A B$ and hao $A B-c y c A B$ gene clusters, Nitrosococcus genomes encode only one copy of each (Klotz et al., 2006; Arp et al., 2007; Campbell et al., 2011a; Klotz and Stein, 2011). The ncyA gene exists as a single copy in all AOB genomes (Klotz and Stein, 2011). In contrast, the complement of quinol-oxidizing electron flow inventory encoded in the genomes of nitrosococci is more diverse than that encoded in betaproteobacterial AOB genomes (Klotz and Stein, 2011). Thus, Nitrosococcus is an ideal model for discriminating differences between signaling- and energy-mediated expression of genes encoding essential inventory for catabolism and chemosynthesis. Thus, far, it has been shown that ammonium induces expression of the amoRCABD gene cluster encoding the AMO complex (Figure 1), whereby the individual overlapping operons in this cluster exhibited different patterns of regulation and expression (El Sheikh and Klotz, 2008; El Sheikh et al., 2008).

In the present study, we used a Nimblegen-platform quadroplex microarray to investigate the differences between ammonium- and hydroxylamine-induced transcriptomes of $N$. oceani after denial of ammonia as an energy source. The premise for the experimental design was that genes similarly regulated between the ammonium and hydroxylamine treatments would be considered as "energy/redox status-regulated," whereas genes more highly expressed under the ammonium compared to the hydroxylamine treatment would be considered as "ammonium-regulated." The results allowed us to discriminate inventory that responds strongly and rapidly to a change

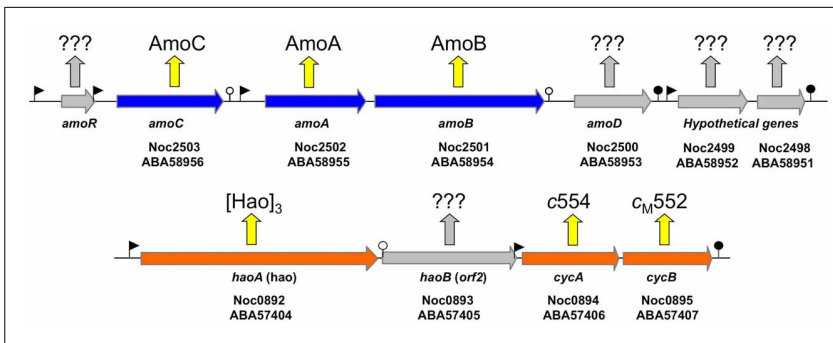

FIGURE 1 | Map of the amo gene cluster based on the genome sequence of $\boldsymbol{N}$. oceani ATCC 19707. Filled arrows represent open reading frames. The promoters and transcriptional terminators are represented by flags and stem loops, respectively. Week terminators are indicated by an open circle. The amoR gene (not annotated in the genome and thus not represented on the array) is unique to Nitrosococcus oceani (strain ATTC 19707, AFC27, AFC132, and C-27) and Noc2499 and Noc2498 are hypothetical genes conserved in the genome sequenced strains of all three species in the genus Nitrosococcus (N. oceani, N. watsonii, and N. halophilus). Identified and hypothetical expression products are given by respective protein annotation or question marks, respectively. 
in cellular redox status from exclusive members of the ammonia stimulon. The global transcriptional responses of $N$. oceani were compared to other $\mathrm{AOB}$ to better understand and define the core function and regulation of obligate ammonia-oxidizing chemolithotrophs.

\section{MATERIALS AND METHODS BACTERIAL GROWTH AND EXPERIMENTAL TREATMENTS}

Nitrosococcus oceani type-strain ATCC 19707 was obtained from the American Type Culture Collection and maintained at a temperature of $30^{\circ} \mathrm{C}$ in the dark without shaking on marine mineral salts medium as described previously (Graham et al., 2011). To attain sufficient biomass, multiple cultures were grown in 0.6- and 1-L batches of medium in 2- and 4-L Erlenmeyer flasks, respectively, and titrated to $\mathrm{pH} 8.0$ daily with $\mathrm{K}_{2} \mathrm{CO}_{3}$. Cells were grown to late exponential growth phase as determined by $\mathrm{NO}_{2}^{-}$concentration, harvested by centrifugation $(8000 \times \mathrm{g}$, $15 \mathrm{~min}$ at $4^{\circ} \mathrm{C}$ ), washed twice with $\mathrm{NH}_{3}$-free growth medium, and resuspended into $800 \mathrm{~mL}$ fresh $\mathrm{NH}_{3}$-free growth medium containing $5 \mathrm{mM}$ HEPES. The resuspended cells were divided into four $200 \mathrm{~mL}$ aliquots for the following experimental treatments: (1) $\mathrm{NH}_{4}^{+}$-Starved: Cells were denied energy and reductant by omitting $\left(\mathrm{NH}_{4}\right)_{2} \mathrm{SO}_{4}$ from the growth medium for $24 \mathrm{~h}$. (2) $\mathrm{NH}_{4}^{+}$-Induced: Induction of gene expression by ammonium was investigated by exposing ammonium-starved cells $(20 \mathrm{~h})$ to $5 \mathrm{mM}\left(\mathrm{NH}_{4}\right)_{2} \mathrm{SO}_{4}$ for $4 \mathrm{~h}$. (3) Control: The control treatment was comprised of cells incubated in growth medium with $5 \mathrm{mM}$ $\left(\mathrm{NH}_{4}\right)_{2} \mathrm{SO}_{4}$ for $24 \mathrm{~h}$. (4) $\mathrm{NH}_{2} \mathrm{OH}$ - Induced: Induction of gene expression by exposure to hydroxylamine was investigated by exposing ammonium-starved cells $(23.5 \mathrm{~h})$ to $0.2 \mathrm{mM} \mathrm{NH}_{2} \mathrm{OH}$ for $30 \mathrm{~min}$. Biomass was collected by centrifugation following the specified exposure times and used immediately for RNA extraction.

\section{RNA EXTRACTION}

RNA was extracted with the FastRNA Pro Blue kit (Qbiogene, Irvine, CA, USA) according to the manufacturer's protocol. RNA pellets were resuspended in $100 \mathrm{~mL}$ of nuclease-free $0.1 \mathrm{mM}$ EDTA (Ambion, Austin, TX, USA). Resuspended RNA was checked for integrity by visualization of ribosomal bands on an Ethidium bromide-stained agarose gel and quantified by absorbance at $260 \mathrm{~nm}$ on a spectrophotometer (Beckman DU 640, Fullerton, CA, USA). Each extraction yielded 15-30 $\mu \mathrm{g}$ total RNA. Intact RNA samples were treated with RQ1 RNase-free DNase (Promega, Madison, WI, USA) according to the manufacturer's recommendations, ethanol-precipitated, and resuspended in $20 \mathrm{~mL}$ of $0.1 \mathrm{mM}$ EDTA and re-checked for degradation. A portion of the RNA was used in cDNA synthesis and the remainder was stored at $-20^{\circ} \mathrm{C}$. RNA was converted to first-strand cDNA using $200 \mathrm{ng}$ of random nonamer primer with Superscript III (Invitrogen, Carlsbad, CA, USA) reverse transcriptase according to the manufacturer's instructions at an extension temperature of $50^{\circ} \mathrm{C}$ for $60 \mathrm{~min}$. A portion of the first-strand cDNA was used in second-strand cDNA synthesis according to the manufacturer's instructions. The second-strand cDNA was shipped to NimbleGen Systems (Reykjavik, Iceland) for processing, labeling and microarray hybridization.

\section{ARRAY DESIGN, HYBRIDIZATION AND ANALYSIS}

The genome sequence from $N$. oceani (GenBank chromosome accession no. CP000127) was used by NimbleGen for microarray design and manufacture. The NimbleGen $4 \times 72 \mathrm{~K}$ multiplex microarray slide contained 72,000 probe sets per array and four arrays per slide. Four replicates of the genome were included per array and six 60-mer probes represented each open reading frame (ORF) in the genome (the finished N. oceani genome is annotated to have 3017 ORFs). A quality control check (hybridization) was performed for each array, which contained on-chip control oligonucleotides. Double-stranded cDNA was random-prime labeled with Cy3-nonamers and hybridized to the microarrays. The microarrays were washed, dried, and scanned at $5 \mu \mathrm{m}$ resolution using a GenePix 4000B microarray scanner (Molecular Devices, Sunnyvale, CA). Data were extracted from scanned images using NimbleScan software (NimbleGen).

\section{MICROARRAY DATA ANALYSIS}

Investigation of reproducible differences between treatments was performed using the CLC Genomics Workbench software package. Data were processed using quantile normalization and background correction was performed using the robust multi-array average (RMA) method. Data were visualized with scatter plots to examine the distribution of hybridizing cDNAs to Nitrosococcus probes (equivalent to NGS reads). Intensities were adjusted to have the same interquartile range. A linear model fit was determined for each gene using the CLC Genomics Workbench.

Expression ratios were calculated from the averages of four independent microarray hybridizations (i.e., a total of 16 spots averaged per gene, per treatment) and presented as: (1) Induction of transcripts responsive to ammonium $\left(\mathrm{NH}_{4}^{+}\right.$-Induced/ $\mathrm{NH}_{4}^{+}$Starved); (2) Induction of transcripts responsive to $\mathrm{NH}_{2} \mathrm{OH}$ $\left(\mathrm{NH}_{2} \mathrm{OH}\right.$-Induced/ $\mathrm{NH}_{4}^{+}$-Starved); (3) Repression or degradation of transcripts from denial of ammonium as an energy source $\left(\mathrm{NH}_{4}^{+}\right.$-Starved/Control); and (4) Transcripts responsive to ammonium in non-starved cells $\left(\mathrm{NH}_{4}^{+}\right.$-Induced/Control). Hybridization results, ratios, and standard deviations from replicate microarray hybridizations are provided in Supplemental Table 1.

\section{RESULTS}

\section{GENE EXPRESSION RATIOS BETWEEN ENERGY-INDUCED vS. STARVED CELLS}

Exposure of $N$. oceani cells to either ammonium or hydroxylamine as an energy source allowed examination of global gene expression as the result of a change in cellular redox status. Steady-state mRNA levels varied from +30 to -16 -fold when provided with ammonium or hydroxylamine relative to cells deprived of energy (Figure 2). Responses to ammonium resulted in greater variation across the genome when compared to responses to hydroxylamine in genes that were under-expressed relative to starved control cells, however, variation in upregulated genes was similar between the two treatments (Figure 2).

Examination of individual genes and gene clusters affected by ammonium or hydroxylamine exposure showed the greatest response in modules for primary and secondary electron flow (Table 1) and carbon fixation (Figure 2; Table 2). It was 
Table 1 | Expression ratios of genes and gene clusters in catabolic modules for "Energy and Primary and Secondary Electron Flow."

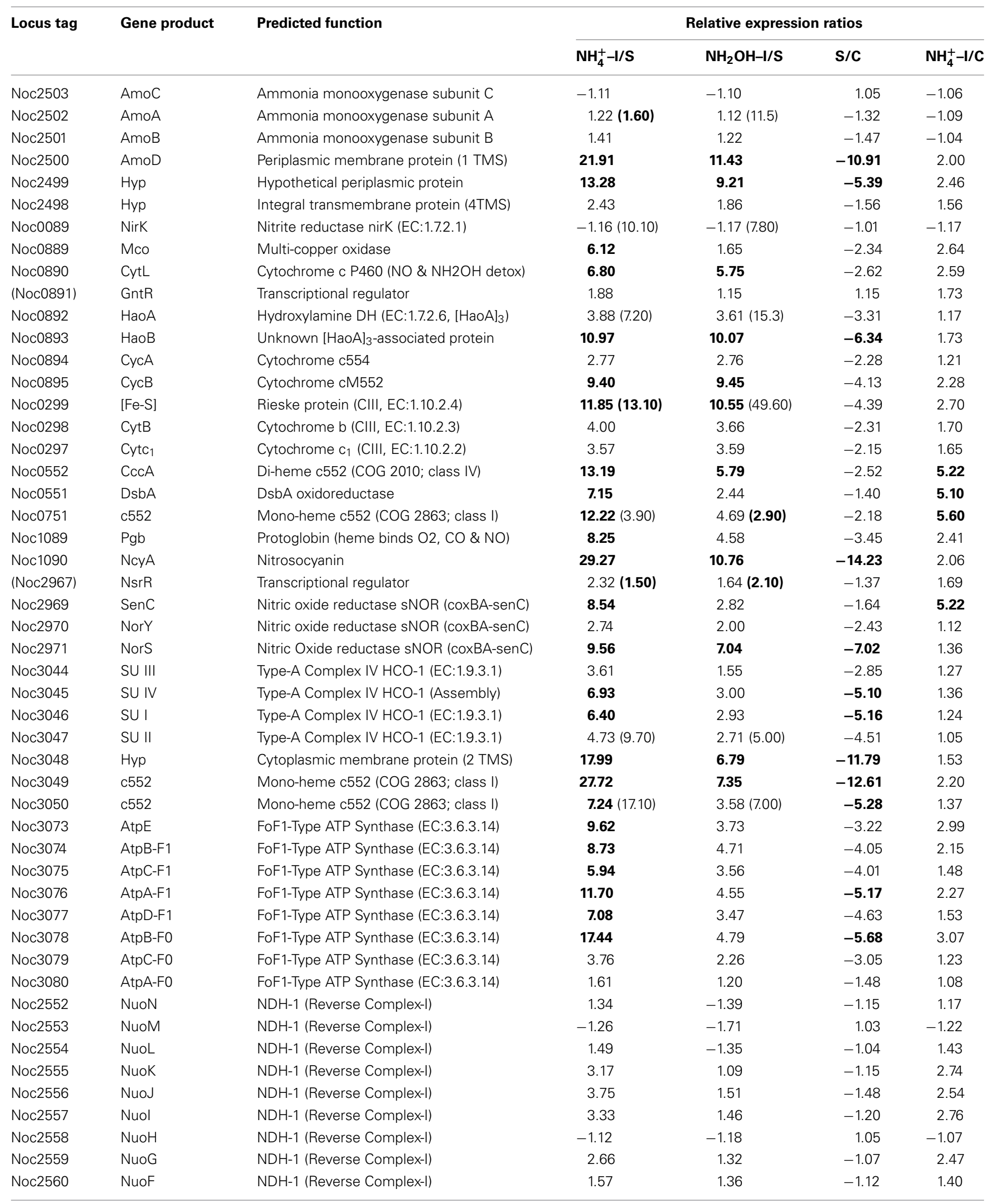


Table 1 | Continued

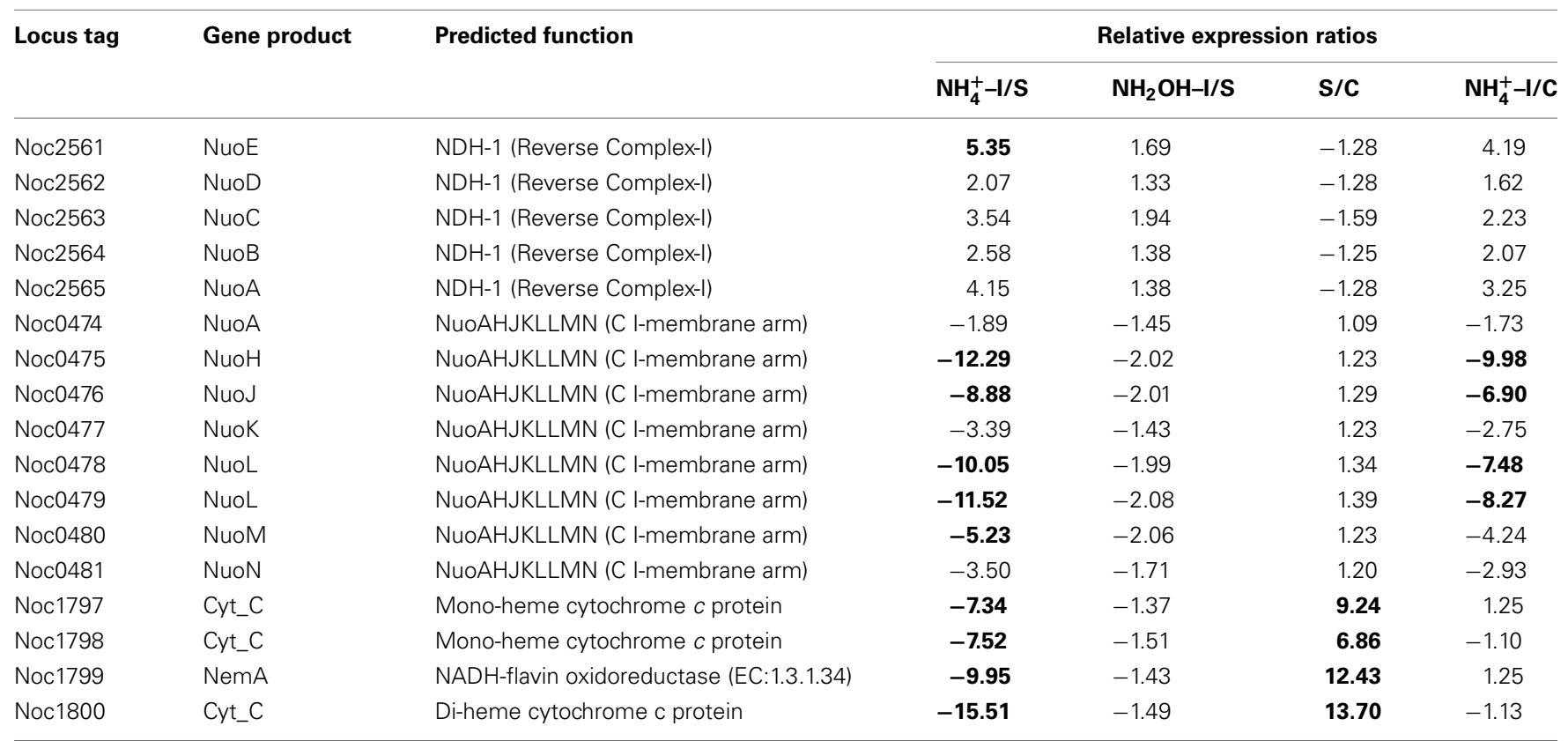

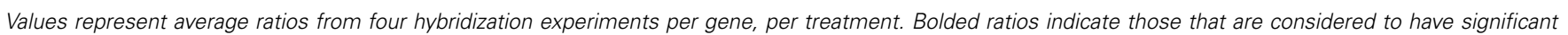

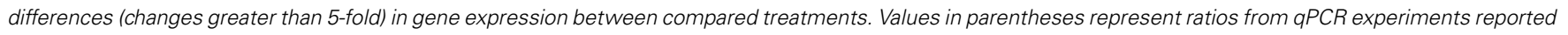

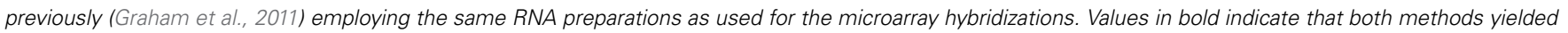
consistent results.

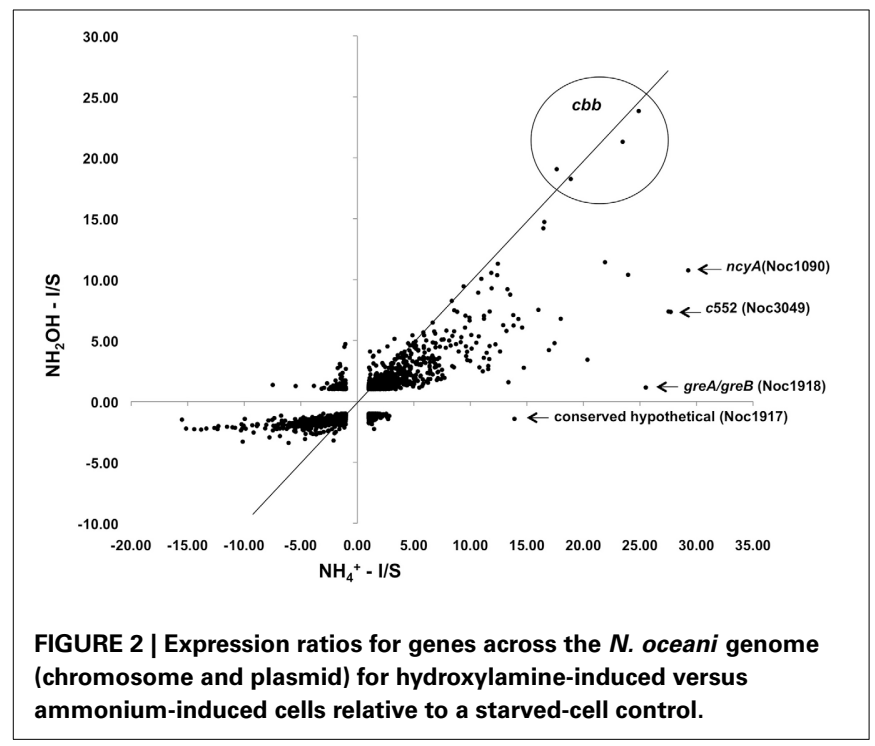

expected that the primary inventory for chemolithotrophic ammonia oxidation ( $a m o C A B$, hao $A B, c y c A B$, and $n c y A$ ), would be highly induced upon exposure to an energy-generating substrate, and particularly to ammonium. However, the steady-state levels of transcripts from ammonia monooxygenase (amo$C A B$, Noc2503, 2502, 2501) and hydroxylamine dehydrogenase (haoA, Noc0892) structural genes were not significantly changed, whereas the transcript levels of other genes in these two clusters (Noc2500, 2499; Noc0893, Noc0895) were significantly increased in response to ammonium or hydroxylamine and decreased in ammonium-starved relative to control cells (Figure 1; Table 1). Similarly, while levels of the $c y c A$ (Noc0894) transcript were not elevated, $c y c B$ (Noc0895) transcript levels were higher after exposure to ammonium or hydroxylamine. mRNA levels of the gene encoding nitrosocyanin (ncyA, Noc1090) were among the most elevated in response to ammonium or hydroxylamine (Figure 2; Table 1), and they were significantly reduced in ammoniumstarved relative to control cells (Table 1). As for carbon fixation and assimilation, genes in the operon encoding Ribulose-1,5bis-phosphate Carboxylase/Oxygenase (RuBisCO) was among the most highly expressed by ammonium or hydroxylamine as were genes in an operon encoding glycolytic enzymes likely involved in gluconeogenesis (Table 2). The gene encoding a key regulatory protein for $\mathrm{N}$-assimilation, $\mathrm{PII}$, was also highly expressed as a result of exposure to ammonium or hydroxylamine (Table 2).

Other noteworthy catabolic inventory induced by ammonium or hydroxylamine included genes encoding cytochrome P460 (cycL, Noc0890), mono- (Noc3049) and di-heme cytochrome c552 proteins (Noc0552), Rieske protein of Complex III (Noc0299), and the NorS component (Noce2971) of cytochrome $c$-linked nitric oxide reductase, sNOR (Table 1). Stress tolerance genes encoding tellurium resistance protein TerB (Noc1001) and the protein chaperone GroES (Noc2922), and a gene encoding the acyl carrier protein AcpP (Noc1664) were also among the most highly induced by exposure to ammonium or hydroxylamine (Table 3).

Data from RT-qPCR assays presented in Table 1 were performed using the same RNA preparations as for microarray hybridizations, employing primer sets designed against core 
Table 2 | Expression ratios of genes and gene clusters in catabolic modules for "Carbon Fixation and Assimilation" and "Nitrogen Assimilation."

\begin{tabular}{|c|c|c|c|c|c|c|}
\hline \multirow[t]{2}{*}{ Locus tag } & \multirow[t]{2}{*}{ Gene product } & \multirow[t]{2}{*}{ Predicted function } & \multicolumn{4}{|c|}{ Relative expression ratios } \\
\hline & & & $\mathrm{NH}_{4}^{+-}-\mathrm{I} / \mathrm{S}$ & $\mathrm{NH}_{2} \mathrm{OH}-\mathrm{I} / \mathrm{S}$ & $\mathrm{S} / \mathrm{C}$ & $\mathrm{NH}_{4}^{+}-\mathrm{I} / \mathrm{C}$ \\
\hline Noc0330 & Hyp & Associated with RuBisCO operon & 17.64 & 19.07 & -2.84 & 6.20 \\
\hline Noc0331 & CbbX & RuBisCO (ATPase) & 24.89 & 23.83 & -4.38 & 5.69 \\
\hline Noc0332 & CbbS & RuBisCO (small subunit) & 18.88 & 18.26 & -11.07 & 1.71 \\
\hline Noc0333 & CbbL & RuBisCO (large subunit) & 23.47 & 21.31 & -12.45 & 1.88 \\
\hline Noc2808 & Tkt2 & Transketolase (EC:2.2.1.1) & 11.20 & 6.79 & -4.51 & 2.49 \\
\hline Noc2807 & GapA & Glyceraldehyde-3-P dehydrogenase (EC:1.2.1.12) & 7.88 & 5.81 & -4.70 & 1.68 \\
\hline Noc2806 & Pgk & Phosphoglycerate kinase (EC:2.7.2.3) & 2.74 & 2.31 & -2.18 & 1.25 \\
\hline Noc2805 & PykF & Pyruvate kinase (EC:2.7.1.40) & 2.17 & 1.62 & -1.40 & 1.55 \\
\hline Noc2804 & ALDOB & Fructose-bis-phosfate aldolase (EC:4.1.2.13) & 5.88 & 4.54 & -3.12 & 1.89 \\
\hline Noc2492 & $\mathrm{RPE}$ & Ribulose-phosfate 3-epimerase (EC:5.1.3.1) & 9.53 & 6.06 & -2.02 & 4.73 \\
\hline Noc2493 & PGLP & Phosphoglycolate phosphatase (EC:3.1.3.18) & 2.59 & 2.43 & -1.57 & 1.65 \\
\hline Noc0715 & $\mathrm{G} \ln B / K$ & Nitrogen regulatory protein P-II & 13.82 & 6.23 & -2.28 & 6.05 \\
\hline Noc2573 & CPS & Carbamoyl-phosfate synthase, small subunit & 6.97 & 2.84 & -1.51 & 4.63 \\
\hline Noc2572 & CPS & Carbamoyl-phoshate synthase, large subunit & 4.96 & 1.56 & -1.39 & 3.59 \\
\hline
\end{tabular}

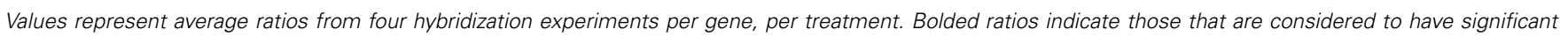
differences in gene expression between compared treatments (changes greater than 5-fold).

catabolic genes as reported elsewhere (Graham et al., 2011). Only few of the ratios derived from RT-qPCR matched those from microarray hybridization experiments; for instance, genes encoding haoA (Noc0892), nirK nitrite reductase (Noc0089) and two genes in the Complex IV terminal oxidase gene cluster (Noc3047, 3050) were highly expressed according to RT-qPCR in cells exposed to ammonium or hydroxylamine, but were not highly expressed according to microarray hybridization. Also surprising was high expression of amoA upon exposure to hydroxylamine, but not to ammonium, according to RT-qPCR, but not microarray hybridization experiments. The pattern of amoA expression using arrays is also in contradiction to prior studies on regulation of the ammonia monooxygenase operon by ammonium in N. oceani, which was assessed by RT-qPCR and Northern analysis (El Sheikh and Klotz, 2008; El Sheikh et al., 2008).

Significantly reduced steady-state transcript levels were identified only when comparing results from ammonium-exposed and starved cells, indicating transcript degradation or gene repression as part of the ammonium-responsive stimulon rather than as a response to a change in cellular redox status.

\section{GENES RESPONSIVE TO AMMONIUM AS A SIGNALING MOLECULE}

Genes for which significant changes in transcript levels were identified after exposure to ammonium, but not to hydroxylamine, relative to both starved and non-starved control cells can be considered bona fide components of the ammonia-responsive stimulon. Such genes with increased transcript levels included those encoding DsbA disulfide oxidoreductase (Noc0551), a monoheme cytochrome c552 (Noc0751), the SenC component of sNOR nitric oxide reductase (Noc2969), two transcriptional regulators (Noc2610, 2010), ribosomal structural proteins (Noc3037, 2122, 0042), flagellar assembly protein FliH (Noc1658), and a ferric uptake regulatory protein (Noc1194) (Tables 1, 3). Genes with decreased transcript levels included several that contribute to synthesis of forward Complex I (Noc0475-0476, 0478-0479), restriction endonucleases and DNA polymerases (Noc0448, 0446, 1203, 2535), flagellar and Type IV pilus proteins (Noc0834, 2365, 2270-2272, 2274), a Czc heavy metal efflux pump (Noc0294), and a hemolysin channel protein (Noc0157) (Tables 1, 3).

A number of genes also showed significant changes in transcript levels upon exposure to ammonium, but not hydroxylamine, relative to the ammonium-starved, but not to the control cells taken directly from batch cultures. Highly expressed genes in this category included those encoding a multi-copper oxidase (Noc0889), clusters encoding Complex IV terminal oxidase (Noc3045, 3036, 3050), $\mathrm{F}_{0} \mathrm{~F}_{1}$ ATPase (Noc3073-3078) and carbamoyl-phosfate synthase (Noc2573-2572), and a very highly expressed sulfate transporter (Noc1626) (Tables 1-3). Genes with reduced transcript levels in this category included a fourgene cluster encoding cytochrome $c$ related proteins (Noc17971800).

\section{DEGRADATION OF TRANSCRIPTS DURING STARVATION FROM AMMONIUM}

Transcript degradation was assessed by comparing expression of genes in ammonium-starved cells relative to non-starved control cells. The most depleted transcripts in starved cells included those encoding the $a m o D$ transcript (member of the amo operon, Noc2500), the haoB transcript (member of the hao operon, Noc0893), ncyA (nitrosocyanin, Noc1090), the nor $S$ transcript (member of the nitric oxide reductase operon, Noc2971), several genes in the Complex IV terminal oxidase gene cluster (Noc3045-3050), transcripts encoding CbbL and CbbS of RuBisCO (Noc0332-0333), transcriptional 
Table 3 | Expression ratios of genes and gene clusters in other functional categories.

\begin{tabular}{|c|c|c|c|c|c|c|}
\hline Locus tag & Gene product & Predicted function & \multicolumn{4}{|c|}{ Relative expression ratios } \\
\hline Noc0448 & HsdR & Type I site-specific deoxyribonuclease & -11.04 & -2.12 & 1.30 & -8.51 \\
\hline Noc0447 & HsdR & Type I restriction-modification system endonuclease & -1.27 & -1.86 & 1.28 & 1.01 \\
\hline Noc0446 & HsdS & Restriction endonuclease S subunit & -10.81 & -2.16 & 1.21 & -8.92 \\
\hline Noc1203 & PnpA & DNA polymerase, beta-like region & -8.15 & -2.21 & 1.42 & -5.74 \\
\hline Noc1202 & DUF86 & Hypothetical & -10.29 & -2.38 & 1.49 & -6.91 \\
\hline Noc1201 & YfiC & N-6 DNA methylase & -5.04 & -1.77 & 1.21 & -4.16 \\
\hline Noc2535 & PnpA & DNA polymerase, beta-like region & -8.05 & -1.92 & 1.21 & -6.67 \\
\hline Noc2536 & PnpB & Nucleotidyltransferase substrate binding protein & -5.35 & -1.43 & 1.19 & -4.48 \\
\hline Noc2010 & DksA & C-4 type zinc finger protein & 16.02 & 7.52 & -2.16 & 7.43 \\
\hline \multicolumn{7}{|c|}{ TRANSLATION } \\
\hline Noc2332 & RplL & Large subunit ribosomal protein L7/L12 & 23.95 & 10.40 & -5.74 & 4.17 \\
\hline Noc2640 & RpmB & Large subunit ribosomal protein L28 & 16.45 & 14.21 & -6.57 & 2.51 \\
\hline Noc2641 & RpmG & Large subunit ribosomal protein L33 & 12.43 & 11.30 & -5.51 & 2.28 \\
\hline Noc2309 & RplF & Large subunit ribosomal protein L6 & 11.44 & 3.99 & -5.10 & 2.24 \\
\hline Noc3037 & RpsT & Small subunit ribosomal protein S20 & 11.18 & 3.58 & -1.63 & 6.86 \\
\hline Noc2319 & RplV & Large subunit ribosomal protein L22 & 10.69 & 8.93 & -5.04 & 2.13 \\
\hline Noc2122 & YhbC & Ribosomal maturation protein & 9.71 & 4.08 & -1.76 & 5.51 \\
\hline Noc0042 & $\mathrm{RpsU}$ & Small subunit ribosomal protein S21 & 5.74 & 1.26 & -1.14 & 5.04 \\
\hline \multicolumn{7}{|c|}{ FLAGELLA/PILI } \\
\hline Noc2273 & PilX & Type IV pilus assembly protein & -3.33 & -1.79 & 1.50 & -2.23 \\
\hline Noc2274 & PilY & Type IV pilus assembly protein PilY1 & -6.61 & -1.97 & 1.26 & -5.25 \\
\hline Noc2275 & PilE & Bacterial general secretion pathway protein $\mathrm{H}$ & -2.78 & -1.48 & 1.27 & -2.18 \\
\hline \multicolumn{7}{|c|}{ TRANSPORT } \\
\hline Noc1626 & Sul1 & Sulfate transporter & 20.35 & 3.42 & -16.51 & 1.24 \\
\hline Noc1194 & Fur & Ferric uptake regulation protein & 6.29 & 1.84 & -1.17 & 5.35 \\
\hline Noc0294 & CzcA & Heavy metal efflux pump; CzcA family & -6.53 & -1.89 & 1.17 & -5.54 \\
\hline \multicolumn{7}{|c|}{ STRESS TOLERANCE } \\
\hline Noc1001 & TerB & Tellurium resistance & 16.54 & 14.73 & -6.64 & 2.50 \\
\hline Noc2922 & GroES & Protein folding chaperone & 14.25 & 6.77 & -2.68 & 5.30 \\
\hline \multicolumn{7}{|l|}{ LIPIDS } \\
\hline Noc1664 & AcpP & Acyl carrier protein; fatty acid biosynthesis & 27.53 & 7.38 & -5.36 & 5.13 \\
\hline Noc0157 & HlyllI & Channel protein, hemolysin III family COG1272 & -13.35 & -2.22 & 1.36 & -9.83 \\
\hline
\end{tabular}

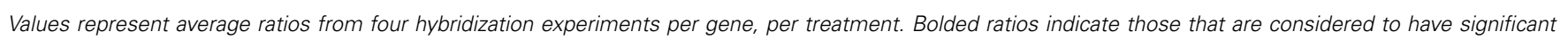
differences in gene expression between compared treatments (changes greater than 5-fold).

elongation factors (Noc1918-1917), a number of ribosomal proteins (Noc2332, 2640, 2641, 2309, 2319), the ammonium-induced sulfate transporter (Noc1626), the TerB tellurium resistance protein (Noc1001), and acyl carrier protein AcpP (Noc1664)
(Tables 1-3). Only the four-gene cluster encoding cytochrome $c$ related proteins with unknown function was represented with higher transcript levels in starved relative to non-starved cells (Noc1797-1800) (Table 1). 


\section{DISCUSSION}

The primary findings from this study are that: (1) N. oceani was far more responsive to general changes in redox/energy status than to ammonium as a signaling molecule alone, (2) genes involved in carbon fixation were among the most highly affected by a change in redox/energy status, which makes sense given that this is the most energy and reductant requiring process in chemolithotrophic metabolism; (3) several genes involved in primary catabolic electron flow were regulated by changes in redox/energy status, however, not all clustered or operonal genes were represented by equal and/or equal changes in transcript levels including those genes shown to be regulated by ammonium in prior studies (SayavedraSoto et al., 1996; El Sheikh and Klotz, 2008; El Sheikh et al., 2008); and (4) transcription of $n c y A$ (nitrosocyanin) was the most highly responsive to changes in redox/energy status, indicating an essential function to bacterial ammonia chemolithotrophy. Patterns of transcript abundance in $N$. oceani were significantly different from those observed in certain marine metatranscriptomes where amoA, amtB (ammonium transporter), and nirK (nitrite reductase) mRNAs from ammonia-oxidizing thaumarchaeota were among the most highly represented (Gifford et al., 2010). This perhaps indicates a different response to redox/energy status between the marine ammonia-oxidizing bacteria and thaumarchaeota. Furthermore, the results suggest that key inventory and/or its principle regulation may be entirely different between representatives of ammonia-oxidizing chemolithotrophs from two domains of life.

Several genes encoding primary catabolic and carbon fixation inventory were responsive to ammonium or hydroxylamine and also exhibited reduced expression during ammonium-starvation. This suggests a direct linkage between energy homeostasis-the provisional usage of catabolic energy and reducing powerwith carbon fixation and oxidative phosphorylation. The role of nitrosocyanin in catalysis and electron transfer has been discussed controversially in the literature without defining its role in ammonia chemolithotrophy other than its exclusivity to obligate ammonia-oxidizing bacteria (Klotz and Stein, 2011). The null hypothesis to disprove in the future is that nitrosocyanin determines whether electrons extracted by $\mathrm{HAO}$ from hydroxylamine will reduce either cytochromes $c 554$ or $c \mathrm{M} 552$. The specific electron acceptor will then determine whether electrons directly enter the quinone pool or whether they become available for distribution to other electron sinks such as sNOR. Given that two electrons can contribute to energy conservation per ammonia molecule oxidized, complemented by the many possible electrogenic and electroneutral electron flow processes in the branched oxidative electron transport chain of Nitrosococcus (Klotz and Stein, 2011; Simon and Klotz, 2013), the need for controlling the direction of electron flow is evident. Increased expression of genes encoding components of AMO, HAO, CytB, cytochrome P460, sNOR, and nitrosocyanin with either ammonium or hydroxylamine suggests that oxidative electron flow favors not only nitrite production but, in particular the removal of nitric oxide by sNOR (reduction to $\mathrm{N}_{2} \mathrm{O}$ ) or cytochrome P460 (oxidation to nitrite) when $\mathrm{NO}$ is produced by oxidation of hydroxylamine
(Stein, 2011). This activity makes sense for maximizing electron flow between AMO/HAO with Complexes III and IV at high substrate oxidation rates by using periplasmic cytochromes and nitric oxide reductase as catabolic overflow electron sinks (Stein, 2011).

Although the ammonia stimulon as revealed from the microarray data was sparsely populated compared to the gene complement regulated by redox/energy status, it can be concluded that increased transcript availability of genes encoding Complex IV and ATPase along with decreased transcript availability of genes encoding forward Complex I suggests a boost to the production of proton motive force and ATP. This result is consistent with the maximization of catabolic electron flow and upregulation of periplasmic electron sinks to optimize electron flow to the terminal oxidase (Stein, 2011).

One caveat of the results presented in Table $\mathbf{1}$ is the lack of consistency between the data sets generated with the microarray approach and in the RT-qPCR experiments. Although neither method revealed increased steady-state levels of amoA mRNA following exposure to ammonium, amoA mRNA levels following exposure to hydroxylamine and haoA and nirK transcript levels following exposure to either ammonium or hydroxylamine were significantly higher when using RT-qPCR compared to employing the microarray approach. It is possible that that the identified differences in both data sets are due to the inherent differences in hybridization kinetics between the two technologies, differential processing that occurs at least in amo (El Sheikh and Klotz, 2008) and hao (Poret-Peterson et al., 2008) transcripts, and differences in location of hybridizing regions across each gene. It is also important to realize that the analysis of both raw data sets utilized different normalization procedures.

The differences observed between techniques suggest that a quantitation of differences in transcriptional regulation and processing should be based on a gene-by-gene analysis using linearized standard templates in order to reveal why transcripts of certain members of gene clusters and operons are being detected at higher copy numbers than others across a microarray. Regardless of which technique is more accurate, when comparing gene expression data in $N$. oceani with that from betaproteobacterial ammonia-oxidizers (Bollmann et al., 2005; Wei et al., 2006; Cua and Stein, 2011; Kartal et al., 2012), it is evident that ammonia-dependent chemolithotrophy does not follow a single regulatory principle. While each phylotype appears to have maintained regulatory principles tied to the history of a given genome, they appear to have also adapted slightly different regulatory features that they acquired together with cohort-specific inventory to maximize their survival and growth, a process that likely also varied based on the environment (i.e., marine vs. freshwater and soil).

Taken together, this study effectively separated the effects of ammonium in its unprotonated form (ammonia) as an energy source from its role as a signaling molecule on regulatory processes in N. oceani that reflect themselves in varying steady-state transcript levels. The experimentally forced changes to cellular 
redox/energy status of $N$. oceani cells exerted a strong effect on inventory implicated in carbon fixation and catabolic electron flow to the terminal oxidase, indicating that these two functions are the most significant to survival and growth of this bacterium. It has been shown before that minuscule concentrations of ammonium are sufficient for the induction of gene expression (El Sheikh and Klotz, 2008; El Sheikh et al., 2008). In the marine environment, obligate ammonia-oxidizing bacteria are likely not thwarted by access to ammonium, but rather by environmental changes that could result in misdirection of electron flow along the catabolic pipeline. The identified coordinated expression of catabolic inventory, periplasmic electron sinks, nitrosocyanin and carbon fixation genes thus suggests that $N$. oceani is well adapted to quickly sense changes in

\section{REFERENCES}

Arciero, D. M., Pierce, B. S., Hendrich, M. P., and Hooper, A. B. (2002). Nitrosocyanin, a red cupredoxinlike protein from Nitrosomonas europaea. Biochemistry 41, 1703-1709. doi: 10.1021/bi 015908w

Arp, D. J., Chain, P. S., and Klotz, M. G. (2007). The impact of genome analyses on our understanding of ammonia-oxidizing bacteria. Annu. Rev. Microbiol. 61, 503-528. doi: 10.1146/annurev.micro.61.080706. 093449

Arp, D. J., Sayavedra-Soto, L. A., and Hommes, N. G. (2002). Molecular biology and biochemistry of ammonia oxidation by Nitrosomonas europaea. Arch. Microbiol. 178, 250-255. doi: 10.1007/s00203-0020452-0

Basumallick, L., Sarangi, R., Debeergeorge, S., Elmore, B., Hooper, A. B., Hedman, B., et al. (2005). Spectroscopic and density functional studies of the red copper site in nitrosocyanin: role of the protein in determining active site geometric and electronic structure. J. Am. Chem. Soc. 127, 3531-3544. doi: $10.1021 /$ ja044412+

Bergmann, D. J., Hooper, A. B., and Klotz, M. G. (2005). Structure and sequence conservation of hao cluster genes of autotrophic ammonia-oxidizing bacteria: evidence for their evolutionary history. Appl. Environ. Microbiol. 71, 5371-5382. doi: $\quad 10.1128 /$ AEM.71.9.5371-53 82.2005

Beyer, S., Gilch, S., Meyer, O., and Schmidt, I. (2009). Transcription of genes coding for metabolic key functions in Nitrosomonas europaea during aerobic and anaerobic growth. J. Mol. Microbiol. Biotechnol. 16, 187-197. doi: 10. $1159 / 000142531$
Bollmann, A., Schmidt, I., Saunders, A. M., and Nicolaisen, M. H. (2005). Influence of starvation on potential ammonia-oxidizing activity and amoA mRNA levels of Nitrosospira briensis. Appl. Environ. Microbiol. 71, 1276-1282. doi: 10.1128/AEM. 71.3.1276-1282.2005

Bollmann, A., Sedlacek, C. J., J.Norton, Laanbroek, H. J., Suwa, Y., Stein, L. Y., et al. (2012). Complete genome sequence of Nitrosomonas sp. Is79-an ammonia oxidizing bacterium adapted to low ammonium. Stand. Genomic Sci. 7, 351-896.

Campbell, M. A., Chain, P. S., Dang, H., El Sheikh, A. F., Norton, J. M., Ward, N. L., et al. (2011a). Nitrosococcus watsonii sp. nov., a new species of marine obligate ammonia-oxidizing bacteria that is not omnipresent in the world's oceans: calls to validate the names 'Nitrosococcus halophilus' and 'Nitrosomonas mobilis.' FEMS Microbiol. Ecol. 76, 39-48. doi: 10. 1111/j.1574-6941.2010.01027.x

Campbell, M. A., Nyerges, G., Kozlowski, J. A., Poret-Peterson, A. T., Stein, L. Y., and Klotz, M. G. (2011b). Model of the molecular basis for hydroxylamine oxidation and nitrous oxide production in methanotrophic bacteria. FEMS Microbiol. Lett. 322, 82-89. doi: 10. 1111/j.1574-6968.2011.02340.x

Cho, C. M.-H., Yan, T., Liu, X., Wu, L., Zhou, J., and Stein, L. Y. (2006). Transcriptome of Nitrosomonas europaea with a disrupted nitrite reductase (nirK) gene. Appl. Environ. Microbiol. 72, 4450-4454. doi: 10.1128/AEM.02958-05

Coleman, N. V., Le, N. B., Ly, M. A., Ogawa, H. E., McCarl, V., Wilson, N. L., et al. (2012). Hydrocarbon monooxygenase in Mycobacterium: recombinant expression of a member of the ammonia monooxygenase

energy availability to optimize growth and survival in a changing environment.

\section{ACKNOWLEDGMENTS}

Martin G. Klotz was funded by the NSF (grants EF-0404129, EF-0541797 and MCB-0948292/1202648) and incentive funds provided by the University of North Carolina. Lisa Y. Stein was funded by a Discovery Grant from the Natural Science and Engineering Research Council of Canada.

\section{SUPPLEMENTARY MATERIAL}

The Supplementary Material for this article can be found online at: http://www.frontiersin.org/Evolutionary_and_Genomic_ Microbiology/10.3389/fmicb.2013.00277/abstract

superfamily. ISME J. 6, 171-182. doi: 10.1038/ismej.2011.98

Cua, L. S., and Stein, L. Y (2011). Effects of nitrite on ammonia-oxidizing activity and gene regulation in three ammoniaoxidizing bacteria. FEMS Microbiol. Lett. 319, 169-175. doi: 10.1111/j. 1574-6968.2011.02277.x

Elmore, B. O., Bergmann, D. J., Klotz, M. G., and Hooper, A. B. (2007). Cytochromes P460 and c'-beta; a new family of high-spin cytochromes c. FEBS Lett. 581, 911-916. doi: 10.1016/j.febslet. 2007.01.068

El Sheikh, A. F., and Klotz, M. G. (2008). Ammonia-dependent differential regulation of the gene cluster that encodes ammonia monooxygenase in Nitrosococcus oceani ATCC 19707. Environ. Microbiol. 10, 3026-3035. doi: $\quad 10.1111 /$ j.1462-2920.2008 01766.x

El Sheikh, A. F., Poret-Peterson, A. T., and Klotz, M. G. (2008). Characterization of two new genes, $a m o R$ and $a m o D$, in the amo operon of the marine ammonia oxidizer Nitrosococcus oceani ATCC 19707. Appl. Environ. Microbiol. 74, 312-318. doi: 10.1128/AEM. 01654-07

Gifford, S. M., Sharma, S., Rinta-Kanto, J. M., and Moran, M. A. (2010). Quantitative analysis of a deeply sequenced marine microbial metatranscriptome. ISME J. 5, 461-472. doi: 10.1038/ismej.2010.141

Graham, J. E., Wantland, N. B., Campbell, M., and Klotz, M. G. (2011). "Characterizing bacterial gene expression in nitrogen cycle metabolism with RT-qPCR," in Methods Enzymol., Vol. 46: Research on Nitrification and Related Processes, Pt B, eds. M.G. Klotz and L.Y. Stein (San Diego, CA: Elsevier Academic Press Inc), 345-372. doi: 10.1016/B978-0-12-386489-5. 00014-2

Hanson, T. E., Campbell, B. J., Kalis, K. M., Campbell, M. A., and Klotz, M. G. (2013). Nitrate ammonification by Nautilia profundicola $\mathrm{AmH}$ : experimental evidence consistent with a free hydroxylamine intermediate. Front. Microbiol. 4:180. doi: 10.3389/fmicb.2013.00180

Hommes, N. G., Sayavedra-Soto, L. A., and Arp, D. J. (2002). The roles of the three gene copies encoding hydroxylamine oxidoreductase in Nitrosomonas europaea. Arch. Microbiol. 178, 471-476. doi: 10.1007/s00203-002-0477-4

Hooper, A. B., Arciero, D. M. Bergmann, D., and Hendrich, M. P. (2005). "The oxidation of ammonia as an energy source in bacteria in respiration," in Respiration in Archaea and Bacteria: Diversity of Procaryotic Respiratory Systems, ed D. Zannoni (Dordrecht: Springer), 121-147.

Hyman, M. R., and Arp, D. J. (1995). Effects of ammonia on the de novo synthesis of polypeptides in cells of Nitrosomonas europaea denied ammonia as an energy source. J. Bacteriol. 177, 4974-4979.

Kartal, B., Wessels, H., van der Biezen, E., Francoijs, K. J., Jetten, M. S M., Klotz, M. G., et al. (2012). Effects of nitrogen dioxide and anoxia on global gene and protein expression in long-term continuous cultures of Nitrosomonas eutropha C91. Appl. Environ. Microbiol. 78, 4788-4794. doi: 10.1128/AEM. 00668-12

Kern, M., Klotz, M. G., and Simon, J. (2011). The Wolinella succinogenes mcc gene cluster encodes an unconventional respiratory sulfite reduction system. Mol. Microbiol. 82, 1515-1530. doi: 10.1111/j.13652958.2011.07906.x 
Kim, H. J., Zatsman, A., Upadhyay, A. K., Whittaker, M., Bergmann, D., Hendrich, M. P., et al. (2008). Membrane tetraheme cytochrome $\mathrm{cm}_{552}$ of the ammonia-oxidizing Nitrosomonas europaea: a ubiquinone reductase. Biochemistry 47, 6539-6551. doi: 10.1021/bi8001264

Klotz, M. G., Arp, D. J., Chain, P. S., ElSheikh, A. F., Hauser, L. J., Hommes, N. G., et al. (2006). Complete genome sequence of the marine, chemolithoautotrophic, ammoniaoxidizing bacterium Nitrosococcus oceani ATCC 19707. Appl. Environ. Microbiol. 72, 6299-6315. doi: 10. 1128/AEM.00463-06

Klotz, M. G., Schmid, M. C., Strous, M., Op Den Camp, H. J., Jetten, M. S., and Hooper, A. B. (2008). Evolution of an octahaem cytochrome c protein family that is key to aerobic and anaerobic ammonia oxidation by bacteria. Environ. Microbiol. 10, 3150-3163. doi: 10.1111/j.14622920.2008.01733.x

Klotz, M. G., and Stein, L. Y. (2008). Nitrifier genomics and evolution of the nitrogen cycle. FEMS Microbiol. Lett. 278, 146-156. doi: 10.1111/j.1574-6968. 2007.00970.x

Klotz, M. G., and Stein, L. Y. (2011). "Genomics of ammonia-oxidizing bacteria and insights to their evolution," in Nitrification, eds B. B. Ward, D. J. Arp, and M. G. Klotz (Washington, DC: ASM Press), 57-93.

O'Mullan, G. D., and Ward, B. B. (2005). Relationship of temporal and spatial variabilities of ammonia-oxidizing bacteria to nitrification rates in Monterey Bay, California. Appl. Environ. Microbiol.
71, 697-705. doi: 10.1128/AEM.71. 2.697-705.2005

Poret-Peterson, A. T., Graham, J. E., Gulledge, J., and Klotz, M. G. (2008). Transcription of nitrification genes by the methane-oxidizing bacterium, Methylococcus capsulatus strain Bath. ISME J. 2, 1213-1220. doi: 10.1038/ismej.2008.71

Sayavedra-Soto, L. A., Hamamura, N., Liu, C.-W., Kimbrel, J. A., Chang, J. H., and Arp, D. J. (2011). The membrane-associated monooxygenase in the butaneoxidizing Gram-positive bacterium Nocardioides sp. strain CF8 is a novel member of the AMO/PMO family. Environ. Microbiol. Rep. 3, 1758-2229. doi: 10.1111/j.17582229.2010.00239.x

Sayavedra-Soto, L. A., Hommes, N. G., and Arp, D. J. (1994). Characterization of the gene encoding hydroxylamine oxidoreductase in Nitrosomonas europaea. J. Bacteriol. 176, 504-510.

Sayavedra-Soto, L. A., Hommes, N. G., Russell, S. A., and Arp, D. J. (1996). Induction of ammonia monooxygenase and hydroxylamine oxidoreductase mRNAs by ammonium in Nitrosomonas europaea. Mol. Microbiol. 20, 541-548. doi: $\quad 10.1046 /$ j.1365-2958.1996. 5391062.x

Simon, J., and Klotz, M. G. (2013). Diversity and evolution of bioenergetic systems involved in microbial nitrogen compound transformations. Bioch. Biophys. Acta. 1827, 114-132. doi: 10.1016/j.bbabio. 2012.07.005

Stein, L. Y. (2011). "Heterotrophic nitrification and nitrifier denitrification," in Nitrification, eds B. B. Ward, D. J. Arp, and M. G. Klotz
(Washington, DC: ASM Press), 95-114.

Stein, L. Y., Arp, D. J., and Hyman, M. R. (1997). Regulation of the synthesis and activity of ammonia monooxygenase in Nitrosomonas europaea by altering $\mathrm{pH}$ to affect $\mathrm{NH}_{3}$ availability. Appl. Environ. Microbiol. 63, 4588-4592.

Stein, L. Y., and Klotz, M. G. (2011). Nitrifying and denitrifying pathways of methanotrophic bacteria. Biochem. Soc. Trans. 39, 1826-1831. doi: 10.1042/BST20110712

Tavormina, P. L., Orphan, V. J., Kalyuzhnaya, M. G., Jetten, M. S. M., and Klotz, M. G. (2011). A novel family of functional operons encoding methane/ammonia monooxygenase-related proteins in gammaproteobacterial methanotrophs. Environ. Microbiol. Rep. 3, 91-100. doi: 10.1111/j.1758-2229. 2010.00192.x

Tavormina, P. L., Ussler, W., Steele, J. A., Connon, S. A., Klotz, M. G., and Orphan, V. J. (2013). Abundance and distribution of diverse membrane-bound monooxygenase ( $\mathrm{Cu}-\mathrm{MMO})$ genes within the Costa Rica oxygen minimum zone. Environ. Microbiol. Rep. 5, 414-423. doi: 10.1111/17582229.12025

Upadhyay, A. K., Hooper, A. B., and Hendrich, M. P. (2006). NO reductase activity of the tetraheme cytochrome $c_{554}$ of Nitrosomonas europaea. J. Am. Chem. Soc. 128, 4330-4337. doi: 10.1021/ja055183+

Walker, C. B., de La Torre, J. R., Klotz, M. G., Urakawa, H., Pinel, N., Arp, D. J., et al. (2010). Nitrosopumilus maritimus genome reveals unique mechanisms for nitrification and autotrophy in globally distributed marine crenarchaea. Proc. Natl. Acad. Sci. U.S.A. 107, 8818-8823. doi: 10.1073/pnas.0913533107

Wei, X., Yan, T., Hommes, N. G., Liu, X., Wu, L., McAlvin, C., et al. (2006). Transcript profiles of Nitrosomonas europaea during growth and upon deprivation of ammonia and carbonate. FEMS Microbiol. Lett. 257, 76-83. doi: 10. 1111/j.1574-6968.2006.00152.x

Conflict of Interest Statement: The authors declare that the research was conducted in the absence of any commercial or financial relationships that could be construed as a potential conflict of interest.

Received: 13 July 2013; accepted: 26 August 2013; published online: 13 September 2013.

Citation: Stein LY, Campbell MA and Klotz MG (2013) Energy-mediated vs. ammonium-regulated gene expression in the obligate ammonia-oxidizing bacterium, Nitrosococcus oceani. Front. Microbiol. 4:277. doi: 10.3389/fmicb. 2013.00277

This article was submitted to Evolutionary and Genomic Microbiology, a section of the journal Frontiers in Microbiology.

Copyright $\odot 2013$ Stein, Campbell and Klotz. This is an open-access article distributed under the terms of the Creative Commons Attribution License (CC BY). The use, distribution or reproduction in other forums is permitted, provided the original author(s) or licensor are credited and that the original publication in this journal is cited, in accordance with accepted academic practice. No use, distribution or reproduction is permitted which does not comply with these terms. 